\title{
DIFICULDADES PARA A INCLUSÃO DAS PEQUENAS PROPRIEDADES RURAIS NA CADEIA PRODUTIVA DA MADEIRA DO ESTADO DO PARANÁ
}

\author{
José Tarciso Fialho ${ }^{1}$, Antonio Rioyei Higa ${ }^{2}$, Anadalvo Juazeiro dos Santos ${ }^{3}$, \\ Jorge Roberto Malinovski ${ }^{2}$ \\ ${ }^{1}$ Eng. Agrônomo, Doutorando em Engenharia Florestal, UFPR, Curitiba, PR, Brasil - tarcisofialho@ yahoo.com.br \\ ${ }^{2}$ Eng. Florestal, Dr., Depto. de Ciências Florestais, UFPR, Curitiba, PR, Brasil - higa@ufpr.br - malinoviski@ufpr.br \\ ${ }^{3}$ Eng. Florestal, Dr., Depto. de Economia Rural e Extensão, UFPR, Curitiba, PR, Brasil - ajsantos@ufpr.br
}

Recebido para publicação: 12/12/2007 - Aceito para publicação: 28/07/2008

\begin{abstract}
Resumo
Este artigo procura discorrer a respeito das principais dificuldades enfrentadas pelas pequenas propriedades rurais (PPR) para a sua inclusão na cadeia produtiva da madeira (CPM), bem como abordar a forma de sua participação nessa cadeia. Buscou-se retratar a percepção dos diversos agentes que atuam ao longo da cadeia produtiva da madeira no estado do Paraná. Trata-se de uma pesquisa descritiva baseada em dados coletados de fontes bibliográficas, assim como de questionários aplicados aos grupos selecionados. Foram considerados três grupos: a) governo (GOV), composto por 81 questionários; b) não-governo (N-GOV), composto por 76 questionários; e c) produtores (PROD), composto por 97 questionários, totalizando 254 questionários. Os resultados demonstraram a baixa participação dos pequenos produtores rurais na CPM, isto é, embora o Valor Bruto da Produção (VBP) florestal do estado venha aumentando a cada ano, eles ainda são meros fornecedores de matéria-prima. Além disso, dão mostras de que recebem pouco apoio governamental, notadamente quanto aos serviços de assistência técnica e de informações de produção, de mercado e de legislação, dificultando sobremaneira a sua inserção na CPM.

Palavras-chave: Inclusão social; pequenas propriedades rurais; cadeia produtiva da madeira.
\end{abstract}

\begin{abstract}
Difficulties to the inclusion of small land proprieties in the wood production chain in the state of Parana. This paper attempts to talk about the main difficulties faced by the Small Land Properties (SLP) in being included in the whole Wood Production Chain (WPC) as well as its way of participation in this chain. It has been pictured the perceptions from all the agents involved in the whole wood production chain in the State of Paraná. This work reflects a descriptive research based on data collected from the literature, as well as from an inquiry form applied to selected groups. Three groups were considered: a) government (GOV), with 81 forms; b) non-government (N-GOV), with 76 forms; and c) smal farmers (PROD), with 97 forms, adding to 254 inquiry forms. The resuslts showed that the smal farmers have low participation in the WPC, it means that eventhogh the State's forest Protuction Gross Value (PGV) has been increasing each year, the smal farmers are still mere wood suppliers only. Other than that demonstrate that they recieve little government support, mainly technical assistance and production, trademarket and legal rules information, obstructing a lot its insetion in the WPC.

Keywords: Social inclusion; small land properties; wood production chain.
\end{abstract}

\section{INTRODUÇÃO}

Ao longo das últimas décadas, as pequenas propriedades rurais paranaenses não vêm recebendo dos governos a atenção necessária para que possam se integrar de forma eficiente na cadeia produtiva da madeira. Isso foi evidenciado pela Organização das Nações Unidas para Agricultura e Alimentação (FAO, 2004), ao afirmar que há dificuldades desses proprietários em se integrar ao processo produtivo, principalmente com as empresas do setor, destacando-se o excesso de burocracia dos órgãos para o 
licenciamento de corte, a deficiência da assistência técnica florestal, a tradição extrativista do produtor rural em relação às florestas, o longo prazo para o retorno do investimento e a legislação ambiental restritiva.

O setor florestal produtivo paranaense, por ser considerado autossuficiente em termos econômicos, ao longo das últimas décadas não vem recebendo dos governos a atenção necessária para o desenvolvimento de uma política consistente sobre a ampliação da base produtiva florestal do estado. Assim, coube ao próprio setor organizado, constituído principalmente pelas empresas florestais, implementar suas próprias estratégias, tendo estabelecido, ao longo desse período, um complexo industrial dos mais modernos do país. Segundo dados da Associação Paranaense de Empresas de Base Florestal (APRE/PR, 2004), o setor florestal, mesmo explorando apenas cerca de 3\% da área territorial do estado, já responde pelo $2^{\circ}$ lugar entre os exportadores do agronegócio paranaense e é o $3^{\circ}$ na pauta de exportação estadual, perdendo apenas para o segmento de grãos e para o setor automobilístico. Isso caracteriza a grande capacidade tecnológica do setor florestal como uma atividade de altíssima capacidade de agregação de valor.

Entretanto, em que pese o sucesso do setor empresarial florestal, os reflexos negativos da quase ausência de uma política florestal produtiva de forma efetiva recaíram sobre os silvicultores, notadamente os pequenos produtores rurais, que, por falta de apoio institucional, não conseguiram se integrar de forma eficiente à cadeia produtiva da madeira (CPM). Assim, embora ao longo dessa cadeia possam se observar ganhos econômicos consideráveis em função do potencial agregador da transformação madeireira, os agricultores, que compõem a base produtiva da floresta não vêm conseguindo aumentar a sua participação de forma significativa, mantendo-se sempre à margem do processo.

De acordo com o Banco Regional de Desenvolvimento do Extremo Sul-BRDE (2006), o estado do Paraná apresenta um real potencial climático adequado para a produção de madeira (maior área plantada de pinus do Brasil, com uma extensão de plantios florestais correspondente a 33\% de toda área cultivada no país), conseguindo manter um nível tecnológico silvicultural compatível com os mais modernos do mundo, dispondo de capacidade competitiva dentro dos parâmetros da sustentabilidade, além de possuir agricultores competentes. Possui, portanto, um conjunto apropriado para a inserção desses agricultores no processo produtivo florestal, ou seja, atributos capazes de gerar renda, emprego e melhoria da qualidade de vida dos produtores e, consequentemente, reduzir o êxodo rural, amenizando a pressão social nos grandes e médios centros urbanos.

Assim, é dentro daquilo que é, e daquilo que poderia ser, em termos de inclusão das PPR na CPM, que foram levantadas as questões relativas aos problemas desta pesquisa, levando-se em conta a percepção dos atores sociais que compõem a cadeia produtiva da madeira no estado do Paraná.

Um dos problemas relativos a essas questões encontra-se associado às dificuldades de informações tecnológicas de uso múltiplo dos solos, bem como de agregação de valor à produção de madeira, necessárias ao estímulo dos pequenos produtores rurais para que possam ingressar de forma competitiva na CPM. Para tanto, questiona-se: na percepção dos atores sociais que compõem a CPM, quais são as principais dificuldades que os pequenos produtores rurais encontram para que possam iniciar, ou agregar mais valor, na atividade florestal produtiva?

Uma das hipóteses da pesquisa parte da premissa de que há falta de apoio significativo do governo quanto à informação e à assistência técnica.

Como objetivo, procurou-se identificar as principais dificuldades enfrentadas pelos pequenos produtores para sua inserção na CPM, bem como identificar como as PPR participam nessa cadeia, na percepção dos atores pesquisados.

Trata-se de uma pesquisa descritiva baseada em dados coletados de fontes bibliográficas, assim como de questionários aplicados aos grupos selecionados. Foram considerados três grupos, a saber: a) grupo governo (GOV), composto por 81 questionários; b) grupo não-governo (N-GOV), composto por 76 questionários; e c) grupo produtores (PROD), composto por 97 questionários.

\section{REVISÃO BIBLIOGRÁFICA}

As pequenas propriedades rurais, embora representem o segmento responsável pela maior parte da produção de alimento do país, nem sempre receberam o devido apoio para se estabelecerem de forma digna no campo. As consequências desse descaso se acumularam sob a forma de mobilização, cujo 
destino foram os grandes centros, transferindo os problemas para o meio urbano, ou seja, passaram a consumir, ao invés de produzir alimento, além de exigirem ainda mais dos governos em termos de infraestrutura de educação, saúde, saneamento e transporte, entre outros. Assim, os governos vêm percebendo que o custo de manutenção desses produtores no meio rural e de sua inclusão nas cadeias produtivas é muito menor do que os investimentos necessários para atendê-los no meio urbano. Mas as políticas públicas destinadas a ampliar exclusivamente a produção familiar começaram a ser aplicadas mais fortemente somente na década de 1990.

De certa forma, os mecanismos de proteção para as PPR também foram sendo motivo de estudos, como o caso de Queiroz (2006), que procurou analisar a proteção constitucional da pequena propriedade rural, principalmente no que se refere à desapropriação para fins de reforma agrária. Segundo o autor, em pelo menos dois dispositivos constitucionais, há expressa referência à pequena propriedade rural, ambos remetendo à lei ordinária a tarefa de explicitar o que se entende como tal. É, pois, com essas variáveis que se passa a analisar duas garantias constitucionais da pequena propriedade rural, quais sejam, a impossibilidade de desapropriação e a impenhorabilidade. Os dispositivos constitucionais são os seguintes: "Art. 185. São insuscetíveis de desapropriação para fins de reforma agrária: I - a pequena e média propriedade rural, assim definida em lei, desde que seu proprietário não possua outra; XXVI - a pequena propriedade rural, assim definida em lei, desde que trabalhada pela família, não será objeto de penhora para pagamento de débitos decorrentes de sua atividade produtiva, dispondo a lei sobre os meios de financiar o seu desenvolvimento".

Regulamentando o art.185, foi editada a lei 8.629/93, que de forma expressa dá o conceito do que sejam a pequena e a média propriedade rural, respectivamente, aquela entre 1 (um) e 4 (quatro) módulos fiscais, e de 4 (quatro) a 15 (quinze) módulos. Sob essa ótica, o problema está resolvido, na medida em que não há mais o que discutir: os imóveis com até 15 módulos fiscais não podem ser desapropriados para fins de reforma agrária, uma vez que a ementa da lei reguladora se refere expressamente ao art. 185 da Constituição Federal.

No entanto, é o Congresso Nacional quem vai estabelecer os parâmetros de classificação quando, no dia 4 de julho de 2006, aprovou o Projeto de Lei que instituiu a Política Nacional de Agricultura Familiar e Empreendimentos Familiares Rurais. Com a aprovação, o agricultor familiar e a agricultura familiar passaram a ser reconhecidos como um segmento produtivo, conforme os parâmetros de enquadramento do Programa Nacional de Fortalecimento da Agricultura Familiar (Pronaf), do Ministério do Desenvolvimento Agrário (MDA). Garantiu-se, assim, a institucionalização das políticas públicas voltadas para esse setor.

De acordo com o MDA (2006), o texto aprovado no Congresso Nacional estabeleceu a articulação das políticas da agricultura familiar, em todas as suas fases de implementação, gestão e execução, com aquelas direcionadas à reforma agrária. O debate sobre a Política Nacional de Agricultura Familiar remonta a 1993, e essa lei serviu para corroborar a necessária descentralização de ações para que se possa alcançar a sustentabilidade ambiental e socioeconômica das pequenas propriedades rurais, assim como a equidade da aplicação de políticas públicas, notadamente pela participação de agricultores familiares na formulação e implementação dessas políticas. A inexistência de classificação do produtor como agricultor ou agricultora familiar - até então existia apenas a definição do que é pequena propriedade rural - gerava uma lacuna conceitual para a aplicação de políticas públicas fundamentais, como a da Previdência Social.

Essa lei acabou por facilitar o atendimento de uma série de demandas que esse segmento já vinha reivindicando, isto é, passou a ser reconhecido como um segmento produtivo, encerrando-se, assim, as dúvidas sobre a sua conceituação legal. Garante também a participação dos agricultores familiares na formulação e implementação das políticas. Surge, ainda, a possibilidade de aplicação de diversas políticas fundamentais para os agricultores familiares, como a da Previdência Social. Além disso, os órgãos governamentais poderão adotar esse conceito para aplicar outras medidas em benefício do segmento, além do Pronaf.

Vale ressaltar que o conceito de agricultura familiar é relativamente recente, pelo menos no Brasil. Falava-se em pequeno produtor, pequeno agricultor, e um pouco antes, ainda se utilizava o termo camponês. Em linhas gerais, um empreendimento familiar tem duas características principais: é administrado pela própria família e nele a família trabalha diretamente, com ou sem o auxilio de terceiros. 
Pode-se dizer também que é, ao mesmo tempo, uma unidade de produção, de consumo e de reprodução social.

Em termos de enquadramento, o Decreto $\mathrm{n}^{\circ}$ 1.946/96 define que devem ser proprietários, parceiros, assentados, posseiros, arrendatários que, cumulativamente:

- utilizam o seu trabalho, ou de sua família, podendo ter até 2 empregados permanentes (ou ajuda sazonal de terceiros);

- não detenham área superior a quatro módulos fiscais;

- tenham, no mínimo, $80 \%$ da renda familiar bruta anual originada da exploração agropecuária (sofre variações periódicas) e residam na propriedade ou em aglomerado rural ou urbano.

Quantitativamente, a agricultura familiar no Brasil é responsável por mais de $40 \%$ do Valor Bruto da Produção Agropecuária e suas cadeias produtivas correspondem a 10\% de todo o PIB do país. Reúne 4,2 milhões de estabelecimentos familiares, representa $84 \%$ dos estabelecimentos rurais e emprega $70 \%$ da mão-de-obra do campo. Além disso, é responsável pela maioria dos alimentos na mesa dos brasileiros: $84 \%$ da mandioca, $67 \%$ do feijão, $58 \%$ dos suínos, $54 \%$ da bovinocultura do leite, $49 \%$ do milho, $40 \%$ das aves e ovos e $32 \%$ da soja, entre outros.

Em especial no caso do Paraná, de acordo com o Ipardes (2003), a sociedade rural é composta, em sua maior parte, por agricultores em regime de economia familiar. O número de estabelecimentos e a área controlada pelos agricultores familiares variam conforme a fonte consultada, mas, segundo o Instituto Nacional de Colonização e Reforma Agrária (INCRA) (2000, citado por Ipardes, 2003), eles detêm $86,9 \%$ dos estabelecimentos rurais do estado e $41 \%$ da área, enquanto que os estabelecimentos controlados por empresários - a denominada agricultura patronal - detêm $12 \%$ dos estabelecimentos e $58,5 \%$ da área. Levando-se em conta apenas o critério de área (quatro módulos rurais, em torno de 50 ha), os agricultores familiares paranaenses representariam $85,9 \%$ dos estabelecimentos e $27,7 \%$ da área. "Assim, a agricultura familiar, com menos de um terço da área agrícola do estado, é responsável por 3/4 do pessoal ocupado" (IPARDES,2003, p. 56).

No que se refere à pequena propriedade rural e aos sistemas agroflorestais, há dificuldades de se desenvolver sistemas que sejam viáveis a curto prazo, dadas as características desse segmento, notadamente quanto à disponibilidade de informações e às tradições típicas que ainda permanecem por trás desse tipo de cultivo (extrativismo, longo prazo e consumo próprio, dentre outros).

\section{Dificuldade dos sistemas de integração produtor-indústria}

Várias são as dificuldades para a inclusão das PPR na CPM, entretanto, as questões relativas à integração com as empresas de transformação são as que mais preocupam, por se tratar de um problema de produção e mercado, isto é, depende do tipo de empresa no processo de integração, bem como da competência do agricultor em se integrar.

De acordo com Mendes (2005), um fator de sucesso que vem se verificando na região Sul do Brasil pode ser creditado à integração denominada floresta-indústria, posta em prática pela maioria das empresas do setor. Nessa perspectiva, tem-se que: "Por integração floresta-indústria entende-se o conjunto de medidas ou ações que promovam uma maior aproximação ou entrosamento dos setores florestais e industriais visando, fundamentalmente, ao aumento do rendimento e melhoria da qualidade dos produtos" (BARRICHELO, 1999, citado por MENDES, 2005, p. 35).

Quanto a esse tipo de integração entre empresa e produtor de madeira, o relatório da FAO (2004) revela cinco modalidades de fomento como as mais comuns na região Sul do Brasil: doação de mudas, venda de mudas, arrendamento, renda antecipada e parceria florestal.

Entretanto, algumas dificuldades dos produtores em aceitar o fomento integrado com as empresas do setor foram identificadas pelo mesmo relatório:

- excesso de burocracia dos órgãos para o licenciamento de corte;

- falta de tradição extrativista do produtor rural em relação às florestas;

- longo prazo para o retorno do investimento (para pinus, entre 15 e 18 anos, dependendo do manejo);

- imprevisibilidade da economia brasileira;

- falta de informações econômicas/técnicas ao produtor (da silvicultura);

- assistência técnica deficiente, tradicionalmente agrícola; 
- legislação ambiental restritiva (corte de florestas nativas ou plantadas).

Vale ressaltar ainda o problema do excesso de burocracia, principalmente na fiscalização da produção florestal, que passou a imperar após os movimentos ambientalistas que se sucederam desde os anos 70 do século passado. Quanto a isso, o próprio MMA chama a atenção: "A desregulamentação do setor reflorestador é essencial. Para se produzir madeira plantada, por exemplo, demanda-se hoje uma série de exigências burocráticas que terminam por afastar os pequenos produtores (BRASIL, 2005, p. 11). A esse respeito, Mendes (2005, p. 25) ressalta que o excesso de normas e controles sobre o setor florestal produtivo tem servido como verdadeiro "desincentivo" ao plantio de florestas: "É preciso, portanto, remover esses entraves para viabilizar a consolidação da crescente contribuição de "florestas plantadas de terceiros', e permitir o efetivo desenvolvimento do 'produtor de florestas' no âmbito das pequenas e médias propriedades rurais".

Em especial, a questão do licenciamento ambiental também se constitui em um obstáculo para a ampliação de áreas florestais, principalmente aos pequenos agricultores, dada a falta de informação e de conscientização dos mesmos. Trata-se do procedimento administrativo pelo qual o Instituto Ambiental do Paraná, ao verificar a satisfação das condições legais e técnicas, licencia a localização, instalação, ampliação e a operação de empreendimentos e atividades utilizadores de recursos ambientais considerados efetivos ou potencialmente poluidores ou daqueles que, sob qualquer forma, possam causar degradação e/ou modificação ambiental, considerando as disposições legais e regulamentares e as normas técnicas aplicáveis ao caso (Resolução $n^{\circ}$ 031/98-SEMA). Para o pedido de Licenciamento Ambiental, o processo administrativo deve ser acompanhado de alguns documentos, que são distintos para cada "tipo" de empreendimento ou fase da Licença (Licença Prévia - LP, ou Licença de Instalação - LI ou Licença de Operação - LO). De forma geral, exige-se o requerimento do pedido de licenciamento, o cadastro da atividade a ser licenciada, a prova da publicação do pedido de licenciamento ambiental efetuado em jornal de circulação e no Diário Oficial, a anuência do município quanto ao uso do solo, a prova do pagamento da taxa ambiental e cópia da licença ambiental anterior. Os demais documentos específicos encontram-se relacionados na Resolução no 031 da SEMA, de 02 de setembro de 1998.

Um dos problemas da legislação ambiental brasileira levantado por Antunes (1998) é que ela trata de forma homogênea situações heterogêneas. Isto é, o Brasil, por suas dimensões continentais, apresenta até entre cidades vizinhas uma enorme diferença em sua geografia, em seu solo e clima, entre outras características. "O ambiente não é, portanto, a soma dos elementos naturais e culturais (ar + água + fauna + bens naturais), mas uma totalidade na qual cada componente afeta ou pode ser afetado pelos outros, independentemente da sua consideração autônoma" (ANTUNES, 1998, p. 46). O bom senso ainda é a melhor solução e, para isso, o Zoneamento Ecológico-Econômico, que foi estabelecido pela Lei 6.938/2001 (regulamentada pelo Decreto 4.297/2002), deveria ser o melhor instrumento administrativolegal para solucionar tanto os aspectos referentes ao licenciamento quanto os da Reserva Legal. Mas, ainda, infelizmente, isso não existe.

Finalmente, quanto ao setor florestal produtivo como um todo, de acordo com a Sociedade Brasileira de Silvicultura (SBS, 2003), algumas dificuldades podem ser identificadas: inexistência de políticas públicas, legislação complexa, autoridade difusa, clandestinidade da atividade madeireira, estigmas setoriais (monoculturas, latifúndios, ocupação de áreas agrícolas, florestas abandonadas, desvalorização da madeira, migrações populacionais e marginalização das comunidades locais).

\section{Equidade e inclusão socioeconômica}

O conceito de equidade é concebido por Sposati (2000) como o reconhecimento e a efetivação dos direitos da população, sem restringir o acesso a eles nem estigmatizar as diferenças que conformam os diversos segmentos que a compõe. Assim, equidade é entendida como a possibilidade das diferenças serem manifestadas e respeitadas, sem discriminação, criando condição que favoreçam o combate das práticas de subordinação ou de preconceito em relação às diferenças de gênero, políticas, étnicas, religiosas, culturais, de minorias etc.

Assim, um dos maiores desafios da atualidade é dotar a população menos favorecida de condições dignas de sobrevivência e cidadania. Portanto, uma das providências fundamentais para superação desse grave problema é a identificação de qual camada da população está mais vulnerável e exposta à exclusão dos meios necessários à sobrevivência e ao acesso aos serviços básicos que tornam o indivíduo integrante de uma sociedade mais justa, equânime e solidária. 
Ainda no que se refere à equidade, vale lembrar o equívoco entre economistas, sociólogos e até de cientistas políticos a respeito da relação entre pobreza e desigualdade, relatado por Veiga (2002, p. 44): "Ao contrário do que pensam, a desigualdade pode até piorar enquanto cai a pobreza. Não é raro que um crescimento econômico contínuo, que eleve o nível de renda de todas as camadas da população, mantenha ou aumente as disparidades entre pobres e ricos". De outra forma, o autor complementa que "a desigualdade só diminui aos poucos, se for submetida a uma árdua, ferrenha, incessante e paciente ofensiva social [...]. Estudos revelam que justamente as sociedades que, no início do processo já eram as menos desiguais, foram as que melhor sustentaram e aproveitaram o crescimento econômico (VEIGA, 2002, p. 45).

Reforçando a tese da iniquidade pela desigualdade, Yamamoto (2003, citado por ARAÚJO, 2006, p. 13) explica que "a maximização da equidade é incompatível com a maximização do processo acumulativo" (p. 47). A classe dominante não pode seriamente comprometer-se com a defesa dos direitos humanos sem se negar como classe, sem deixar de ser dominante.

O Brasil se destaca pela desigualdade social, com um verdadeiro abismo entre ricos e pobres, embora essa distância tenha aumentado no mundo na última década, como alerta a Organização das Nações Unidas (ONU) em seu relatório intitulado "A Situação Social Mundial de 2005" (FUNDEP, 2006). No documento, a ONU utiliza esse argumento para defender que o crescimento econômico, por si só, não é panacéia para resolver os problemas do desenvolvimento. Considerando os países subdesenvolvidos, mais de 1,1 bilhão de pessoas vivem em estado de pobreza. Isso significa que, de cada três habitantes do planeta, um está abaixo da "linha de pobreza", sobrevivendo com menos de US\$ 1 por dia. O documento revela que o Brasil está entre os três países mais desiguais do mundo, classificado como $63^{\circ}$ país em qualidade de vida de uma lista de 177 países, em que os $10 \%$ mais abastados têm uma renda equivalente a 32 vezes o que recebem os $40 \%$ mais pobres. São 63 milhões de brasileiros que vivem em situação de indigência. Na área rural, são 10 milhões de pessoas nessa situação, e é onde a situação é mais crítica em termos de saneamento e onde apenas $35 \%$ da população têm acesso a serviços básicos sanitários, além do abastecimento de água ser altamente deficiente, com apenas $58 \%$ da população tendo acesso a água potável (UNICEF, 2004).

Contudo, Demo (1996) assegura que o centro da exclusão não é a pobreza decorrente da insuficiência de renda, mas a pobreza decorrente do problema da desigualdade. A insuficiência de renda representa um fenômeno crítico na vida das famílias, mas é, sobretudo, decorrência da precariedade histórica da cidadania.

Assim, debater inclusão social no Brasil e, em especial, na área rural, é questão mais complexa, tendo em vista focar a miséria de milhões de pessoas com ínfima renda mensal, cujo acesso aos serviços básicos de saúde, educação, informação e desenvolvimento social é seriamente limitado ou, até mesmo, inexistente.

Mas, no que se refere ao meio rural, algumas considerações devem ser acrescidas à análise da inclusão. Ou seja, as características do meio rural também vêm se alterando ao longo do tempo, apresentando uma diversificação crescente de atividades econômicas que elas oferecem à população. Silva (1999), por exemplo, analisou a importância das rendas não-agrícolas para o meio rural brasileiro e concluiu que não se pode caracterizar esse meio somente como agrário. E foi além: o comportamento do emprego rural, principalmente dos movimentos da população residente nas zonas rurais, não pode mais ser explicado apenas a partir do calendário agrícola e da expansão/retração das áreas e/ou produção agropecuárias. Há um conjunto de atividades não-agrícolas, tais como a prestação de serviços, o comércio e a indústria, que respondem cada vez mais pela nova dinâmica populacional do meio rural brasileiro. Como complemento a essa idéia, Veiga (2002) ressalta que o entendimento do processo de urbanização do Brasil é atrapalhado por uma regra muito peculiar, que é única no mundo. Segundo o autor, em nosso país, considera-se urbana toda sede de município (cidade) e de distrito (vila), sejam quais forem suas características. É absolutamente compreensível que poucos saibam que um terço da população brasileira é rural e que essa proporção poderá não diminuir nas próximas décadas.

Isso significa que a diversificação da área rural constitui-se em uma nova forma de organização de atividades que a tornam distinta das características urbanas, apresentando, inclusive, algumas vantagens, tendo em vista que reduz a necessidade de políticas compensatórias e oferece espaço para negociações entre os conservacionistas ambientais da classe média e os agricultores produtivistas (SARACENO, 1994). Relativamente a isso, a Embrapa (2005) apresenta uma nova e moderna agricultura 
tropical que está enriquecendo o Brasil e melhorando a vida, não apenas dos agricultores, mas de todos os brasileiros. Em seu estudo sobre "a nova agricultura tropical", revela uma maior democratização embutida no novo processo de modernização, caracterizada pelo acesso mais fácil dos pequenos agricultores à nova tecnologia de produção. Chama a atenção, ainda, para o fato de que "cada $10 \%$ de crescimento da agricultura, gera de $5 \%$ a $9 \%$ de crescimento na cidade, com enormes impactos sociais positivos e realizando velhos sonhos da cidadania brasileira" (EMBRAPA, 2005). Trata-se, portanto, de uma agricultura enquadrada nos princípios capitalistas e integrada ao meio urbano, gerando renda e auxiliando no desenvolvimento do país. Dessa forma, o seu sucesso acaba por propiciar a criação de mais empregos nas cidades, mais renda, vagas nas escolas, leitos nos hospitais, habitação e saneamento, melhorando, consequentemente, a expectativa de vida de todos. "Está reduzindo a mortalidade e o trabalho infantil, ou seja, está interiorizando o desenvolvimento" (EMBRAPA, 2005).

\section{Certificação da produção florestal}

Segundo Ângelo (2002), regra geral, madeira certificada é sinônimo de qualidade, de confiabilidade e de ser ambientalmente correto, na produção de bens de consumo advindos da floresta. Em verdade, essa certificação possibilita ao produtor de bens madeiráveis a condição de enviar ao consumidor uma mensagem sobre a boa origem da matéria-prima de que ele faz uso. Vale ressaltar que a questão da certificação não se limita ao adequado manejo florestal, mas, sobretudo, à correta gestão da produção florestal, envolvendo os aspectos sociais, levando-se em consideração não somente o cumprimento de legislação trabalhista, mas também as relações com a comunidade.

No Brasil, há dois tipos de certificação florestal em vigor: um coordenado pela Forest Stewardship Council (FSC), representado no país pelo Conselho Brasileiro de Manejo Florestal (CBMF), e outro denominado Programa Brasileiro de Certificação Florestal (Cerflor), desenvolvido pelo Sistema Brasileiro de Avaliação da Conformidade (Sbac), implantado e gerenciado pelo Inmetro. Além disso, duas são as modalidades mais comuns de certificação aqui utilizadas, sendo uma delas dirigida ao manejo florestal e a outra referente à cadeia produtiva, denominada Cadeia de Custódia (ou CoC).

O FSC (2005) é uma organização internacional sem fins lucrativos, fundada em 1993 para apoiar o gerenciamento ambientalmente adequado, socialmente benéfico e economicamente viável das florestas mundiais. Trata-se de uma associação composta por grupos diversos, representantes das áreas ambientais, sociais, do comércio madeireiro, de profissionais de florestamento, de pesquisadores e cientistas florestais, de organizações de povos indígenas, de comunidades florestais, bem como de organizações de certificação de produtos florestais de todo o mundo. A associação está aberta a todos os que estão envolvidos em florestamento ou produtos florestais e compartilham seus propósitos e objetivos. O FSC significa Conselho de Manejo Florestal, e é o resultado de uma iniciativa para a conservação ambiental e desenvolvimento sustentável das florestas mais significativas, na qual se envolveram instituições das mais diferentes áreas de 34 países. O selo FSC é uma garantia da origem. Ele atesta que a madeira (ou outro insumo florestal) utilizada num produto é oriunda de uma floresta manejada de forma ecologicamente adequada, socialmente justa e economicamente viável, e cumpre todas as leis vigentes. O selo serve para orientar o consumidor consciente a optar por um produto que não degrade o meio ambiente e contribua para o desenvolvimento sustentável. Assegura a manutenção da floresta, bem como o emprego e a atividade lucrativa que ela proporciona. A certificação é voluntária e depende de iniciativa da empresa ou organização interessada.

A outra modalidade de certificação destina-se aos produtos intermediários (insumos) ou finais, também conhecida como $\mathrm{CoC}$. Ela atinge, além da certificação das operações florestais, a rastreabilidade da matéria-prima da floresta em todas as etapas de transformação do produto, até o consumidor final. Vale ressaltar que esse processo visa assegurar que os materiais já certificados não se misturem com os não-certificados, isto é, descreve e controla o processo, rota ou cadeia que a matéria-prima certificada percorre, visando garantir aos consumidores que o produto que irão adquirir faz uso de matéria-prima certificada.

Segundo o Relatório de Atividades do FSC-Brasil (FSC, 2005), em 2002, o FSC Internacional iniciou as discussões para a criação de uma política que pudesse facilitar o acesso à certificação para operações florestais com manejo em pequena escala e baixa intensidade (SLIMF, do inglês Small and Low Intensity Managed Forests). A política SLIMF foi aprovada em novembro de 2003 durante um encontro do Conselho de Diretores do FSC em Bonn, Alemanha, e, a partir de 2004, algumas 
certificadoras já utilizam os novos procedimentos em campo. Assim, existe a possibilidade de se discutirem indicadores apropriados para pequenos produtores interessados em certificar suas plantações florestais para todo o país, principalmente com as perspectivas do crescimento do fomento florestal para reflorestamento com espécies como eucalipto e pinus em pequenas propriedades.

Nesse caso, para as PPR, a questão social merece atenção à parte, tendo em vista constituir-se em uma nova vertente dentro do aspecto florestal e que vem se transformando em uma preocupação global, dado seus aspectos comunitários, de emprego e de sobrevivência. A literatura é farta no que se refere às questões mais ligadas aos aspectos produtivistas e de mercado, deixando de lado as questões sociais, isto é, nem sempre atraíram as atenções dos técnicos, administradores e cientistas. Mas, a partir da década de 1980, essa realidade vem mudando e os aspectos sociais vêm ganhando espaço na mídia nacional e internacional. Assim, temas relativos ao desemprego e à exploração infantil, bem como condições adequadas de trabalho, vêm se destacando nos estudos técnicos e na definição de padrões de produção florestal. O Princípio 04, dos Princípios e Critérios do Conselho de Manejo Florestal (FSC, 2006), trata das relações comunitárias e dos direitos dos trabalhadores. A idéia é que as atividades de manejo florestal devem manter ou ampliar o bem-estar social e econômico dos trabalhadores florestais e das comunidades do entorno/área de influência da Unidade de Manejo Florestal (UMF), cujo princípio considera que (FSC, 2006):

- devem ser dadas às comunidades inseridas ou adjacentes oportunidades de emprego, treinamento e outros serviços;

- o manejo florestal deve alcançar ou superar todas as leis e normas relacionadas à saúde e à segurança dos trabalhadores e seus familiares;

- devem ser garantidos os direitos dos trabalhadores de se organizarem e voluntariamente negociarem com seus empregadores conforme descrito nas Convenções 87 e 98 da Organização Internacional do Trabalho (OIT);

- o planejamento e a implantação de manejo florestal devem incorporar os resultados das avaliações do impacto social;

- devem ser adotados mecanismos apropriados para se resolverem queixas e se providenciar compensação justa em caso de perdas ou danos que afetem os direitos legais ou tradicionais, a propriedade, os recursos ou a subsistência da população local.

De acordo com Kengen (2005), na publicação sobre a situação florestal mundial da FAO (State of the World's Forests, 1999), foram levantadas algumas questões sobre certificação e os pequenos proprietários:

- As exigências para certificação discriminam as pequenas plantações florestais.

- Os procedimentos para certificação e os processos de controle da certificação limitam a liberdade dos pequenos proprietários de tomarem decisões sobre os usos alternativos da terra.

- É extremamente expensiva para pequenas áreas de florestas.

- Muitos dos princípios e critérios para certificação não refletem as práticas de manejo florestal que são apropriadas para as pequenas propriedades.

- Muitas das exigências quanto aos aspectos sociais e ambientais não são apropriadas para pequenos proprietários; na verdade, são relevantes para as grandes áreas ou para o país como um todo.

Portanto, a internalização desse processo entre pequenos produtores florestais demandará tempo e esclarecimento. Complementando, segundo Mattos; Schaitza e Ahrens (2005), desde o ano de 2000 houve um grande aumento da área de florestas certificadas no mundo. Entretanto, em muitos países, a certificação de pequenas áreas, individualmente ou em grupo, tem sido difícil (SCRASE, 2000, citado por MATTOS, SCHAITZA e AHRENS, 2005). No Brasil ainda existe uma escassez acentuada de informações sobre as vantagens para os pequenos agricultores e sobre os principais entraves de sua participação, apesar do grande interesse de produtores florestais e organizações certificadoras. As regiões de Erechim e Bocaiúva do Sul, respectivamente no Rio Grande do Sul e no Paraná, foram escolhidas para o desenvolvimento dos primeiros estudos da Embrapa Florestas sobre as dificuldades que deveriam ser superadas pelos pequenos produtores florestais para sua entrada no mercado da certificação florestal. Segundo Mattos et al. (2005), percebe-se que os principais problemas são: 
- a madeira é vendida localmente, sem demanda por matéria-prima certificada. As pequenas serrarias que comercializam madeira para outros mercados não estão associadas aos mercados de madeira certificada;

- o custo da certificação ainda é indefinido;

- aspectos técnicos da certificação são desconhecidos pelos produtores rurais (plano de manejo, inventário, mapas, monitoramentos etc.);

- procedimentos de documentação não são rotineiros para a maioria dos pequenos produtores envolvidos;

- falta de informações sobre certificação florestal para o produtor rural, em linguagem apropriada;

- falta de mapas adequados com a delimitação das áreas de conservação/preservação e limites da propriedade;

- desconhecimento ou ausência de equipamentos de proteção individual para empregados ou para o produtor rural que também desempenha atividades na manutenção e exploração da unidade florestal.

Vale ressaltar algumas dificuldades apontadas pela Abimci (2005), quando se busca a certificação florestal para pequenos agricultores:

- adequação legal da organização (fundiário e ambiental);

- organização em grupos (cooperativas, associações e outros);

- dificuldade para a composição do capital inicial;

- escala de produção;

- comercialização e escoamento da produção;

- custos do processo.

Finalmente, vale ressaltar que esse problema não é exclusivo do Brasil, conforme descreve Aicher (2005): “A estandardização dos padrões do manejo abala as relações entre pequenos produtores e florestas na Alemanha. Eles opõem-se à certificação porque lhes parece absurda e porque ela é um processo caro para donos de pequenas e médias propriedades".

\section{MATERIAL E MÉTODOS}

\section{Enfoque metodológico}

A orientação metodológica na pesquisa bibliográfica (dados secundários) baseou-se em aspectos sistêmicos interdisciplinares envolvendo conhecimentos das diversas áreas que constituem o setor florestal dentro da abordagem de sustentabilidade, tanto no que se refere às suas características técnicas (de ordem ecológica, econômica e social) quanto administrativas, enfocando principalmente a área da política governamental estadual para o setor.

A pesquisa de campo (dados primários) foi desenvolvida com base em dois enfoques metodológicos que interagem: 1) positivista, procurando estabelecer comparações numéricas ou quantitativas para auxiliar na mensuração das diversas variáveis que interferem na cadeia produtiva florestal (os dados foram obtidos por meio de questionários); e 2) fenomenológico, visto ser o objetivo central dessa pesquisa o estudo da percepção dos diversos atores dentro da cadeia produtiva da madeira. Significa valer-se da vivência e experiência de vida dos entrevistados, atendendo aos pressupostos fenomenológicos, conforme assinala Gil (1999, p. 32): "O intento da fenomenologia é, pois, o de proporcionar uma descrição direta da experiência tal como ela é...", acrescentando a seguir: "A fenomenologia ressalta a idéia de que o mundo é criado pela consciência, o que implica o reconhecimento da importância do sujeito no processo de construção do conhecimento" (GIL, 1999, p. 33).

\section{Dados secundários}

Para este tipo de pesquisa, foram realizadas consultas em fontes documentais e bibliográficas com ênfase na avaliação qualitativa e interpretação descritiva dos conteúdos. Torna-se necessário enfatizar a análise crítica da exploração florestal, sob o prisma da interdisciplinaridade dos saberes e da sustentabilidade socioambiental que envolve a Cadeia Produtiva da Madeira, tendo por base revistas científicas, boletins técnicos, livros especializados e teses. As novas tecnologias de acesso à informação 
também foram utilizadas por intermédio da internet em páginas oficiais e de fontes científicas. Finalizando, os dados secundários foram levantados por meio de textos, tabelas, mapas e quadros disponibilizados pelas entidades ou mediante a consulta a especialistas nas áreas ligadas ao setor florestal, como a Secretaria de Estado da Agricultura e do Abastecimento e o Departamento de Economia Rural (SEAB/Deral), a Secretaria de Estado do Meio Ambiente e o Instituto Ambiental do Paraná (Sema/IAP), o Instituto Agronômico do Paraná (Iapar), o Instituto Brasileiro de Geografia e Estatística (IBGE), o Instituto Paranaense de Desenvolvimento Econômico e Social (Ipardes), a Universidade Federal do Paraná (UFPR), a Associação Paranaense de Empresas de Base Florestal (Apre), a Sociedade Brasileira de Silvicultura (SBS), a Associação Brasileira da Indústria de Madeira Processada Mecanicamente (Abimci), a Associação Brasileira de Produtores de Florestas Plantadas (Abraf), o Banco Nacional de Desenvolvimento Econômico e Social (BNDES), o Banco Regional de Desenvolvimento do Extremo Sul (BRDE), a Empresa Brasileira de Pesquisa Agropecuária (Embrapa Florestas), a Organização das Nações Unidas para a Alimentação e a Agricultura (FAO), o Instituto Brasileiro do Meio Ambiente e dos Recursos Naturais Renováveis (Ibama), o Instituto de Pesquisas e Estudos Florestais (Ipef) e o Ministério do Meio Ambiente (MMA), entre outros.

\section{Dados primários}

Trata-se de uma pesquisa descritiva de campo "dedicada ao tratamento da face fatual da realidade onde se produz e analisa dados" (DEMO, 2000, p. 21). Nesse caso, o pesquisador levanta, registra, descobre a frequência de fenômenos, analisa e correlaciona fatos sem manipulá-los, isto é, objetiva conhecer e interpretar a realidade sem nela interferir para modificá-la (CHURCHILL, 1987). Foi realizada através da aplicação de questionários estruturados direcionados, envolvendo os principais atores que compõem a CPM. Quanto à abordagem, optou-se pela pesquisa qualiquantitativa, procurando, por um lado, traduzir em números as percepções dos entrevistados, cujas informações foram classificadas e analisadas através de técnicas estatísticas e, por outro, interpretar os fenômenos e a atribuição qualitativa de seus significados.

\section{Universo e amostra da pesquisa}

Considerou-se como universo da pesquisa todo o estado do Paraná, porém, como amostra, selecionou-se a região de Curitiba, tendo em vista sua importância no segmento florestal, representando a primeira mais expressiva região do estado em termos de Valor Bruto da Produção (VBP), juntamente com a tradicional região de Ponta Grossa (SEAB/Deral/DEB, 2005). Vale salientar a evolução do VBP florestal que a região de Curitiba experimentou do ano de 1998 até 2005, praticamente dobrando a sua participação, passando de $18 \%$ em 1998, para 34\% em 2005. Além disso, a região de Curitiba foi selecionada dada a facilidade de obtenção dos dados, cuja coleta se deu com técnicos da SEAB, Emater, Iapar, Ceasa e Codapar e com alunos da Faculdade Internacional de Curitiba. Considerando essa região, foram selecionados alguns municípios, cuja economia encontra-se relacionada à atividade florestal, medida pelo VBP na Região de Curitiba e cujo extrato fundiário indica uma grande concentração de pequenos agricultores. Considerou-se como pequeno agricultor a mesma classificação estabelecida pelo Pronaf (Programa Nacional de Fortalecimento da Agricultura Familiar, do Ministério do Desenvolvimento Agrário - MDA), dentro das características que foram discutidas anteriormente.

Quanto aos atores pesquisados, utilizou-se amostra de conveniência, extraída a partir de técnicos especializados da área florestal, empresas ou organizações não-governamentais e produtores rurais envolvidos com a questão florestal, que satisfaziam as restrições da pesquisa. Para facilitar a compreensão, as características dos atores pesquisados encontram-se classificadas em três níveis (GOV, N-GOV e PROD) assim descritos:

1. GOVERNO (GOV ): Secretaria de Estado da Agricultura e do Abastecimento (SEAB) técnicos que têm relação com a atividade florestal e técnicos administrativos lotados na sede e no campo (da administração direta e de suas vinculadas: Emater, Iapar, Codapar, Ceasa, Claspar); Secretaria de Estado do Meio Ambiente (SEMA) - técnicos que se relacionam com a atividade florestal e técnicos lotados na sede e no campo (administração direta e vinculadas: IAP e SUDERHSA); outras secretarias do governo (SEPL e SEIM).

2. NÃO-GOVERNO (N-GOV) - empresas madeireiras indicadas pela Associação Paranaense de Empresas de Base Florestal (Apre); universidades estaduais e federais, com cursos relacionados com a 
área florestal; professores universitários do curso de Engenharia Florestal da UFPR; colégios agrícolas estaduais; ONGs ligadas à área florestal; cooperativas de produção agrícola; associação de agrônomos; associação de engenheiros florestais; associação de técnicos agrícolas; Ibama (regionais do Paraná); Embrapa Floresta; Apepa (Associação Paranaense das Empresas de Planejamento Agrícola); Associação de Municípios do Paraná (AMP); deputados estaduais e federais que têm vínculo com a atividade florestal; Crea (regionais do Paraná); técnicos específicos de atuação relevante no setor florestal.

3. PRODUTORES RURAIS (PROD) - apenas pequenos produtores, classificados no Pronaf, que se localizam na região metropolitana de Curitiba, cujas propriedades estejam relacionadas com a atividade florestal (cerca de 2.500 propriedades).

A amostra foi definida tendo por base o cálculo estatístico. Assim, o tamanho mínimo da amostra foi estabelecido para cada classe de universo considerando-se a fórmula aproximada (BARBETTA, 2002, p. 45):

$$
\begin{gathered}
\mathrm{n}_{0}=1 / \mathrm{E}^{2_{0}} \\
\mathrm{n}=\left(\mathrm{N} \times \mathrm{n}_{0}\right) / \mathrm{N}+\mathrm{n}_{0}
\end{gathered}
$$

onde: $\mathrm{n}_{0}$ : fator de cálculo amostral; n: amostra aleatória simples; $\mathrm{E}_{0}$ : erro amostral tolerável; N: tamanho da população

Pretendeu-se, assim, analisar variáveis nominais ou ordinais em uma população finita. Estabeleceu-se, dessa forma, um nível de significância prefixado de 5\%, o que corresponde a um nível de confiabilidade de $95 \%$ sobre os resultados da pesquisa. Uma vez conhecido o tamanho da amostra, foram enviados cerca de 650 questionários, tendo sido respondidos 254 (cerca de 40\%).

\section{Coleta de dados}

O levantamento dos dados é do tipo survey, descritivo, que, segundo Pinsonneault e Kraemer (1993), permite utilizar instrumentos qualiquantitativos, atendendo à complexidade do objeto em estudo, além de dar conta de questões subjetivas, que não podem ser analisadas tão somente a partir da operacionalização de variáveis quantitativas.

Segundo Triviños (1987), independentemente do tipo de coleta de informações, para obtenção de resultados científicos no campo das ciências humanas e sociais, as informações devem apresentar coerência, consistência, originalidade e objetividade, de acordo com os aspectos de critérios internos de verdade e de critérios externos de intersubjetividade.

$\mathrm{O}$ instrumento utilizado para a coleta dos dados primários foi o questionário estruturado, aplicado aos grupos selecionados (GOV, N-GOV e PROD). Segundo Camargo (2000, p. 31), "de nada adianta medir de forma confiável um construto que não seja o que queremos". Assim, sugere o autor que a validade de conteúdo do questionário pode ser realizada "por um conjunto de revisores que possuam algum conhecimento sobre o tema em pesquisa". Busca, portanto, verificar se ele contém tudo o que deveria e se não incorpora, também, aquilo que não deveria. Nesse caso, cada questão teve sua elaboração não só ancorada na revisão da literatura realizada, mas também na experiência de vida acadêmica e técnica dos autores, bem como na troca de conhecimentos entre os autores e as equipes técnicas da Seab, Sema, Emater, IAP, Suderhsa, Iapar, Embrapa-Floresta e UFPR, entre outros.

Assim, o questionário foi composto por blocos de questões fechadas (perfil, avaliações gerais, padrões de comportamento etc.) e um bloco de questões abertas (motivações, sugestões, pontos fortes e fracos etc.). Eles foram aplicados de forma direta (aplicado pelo pesquisador ou equipe treinada) e de forma indireta (enviado ao entrevistado e recolhido posteriormente, ou, ainda, via e-mail, através da internet). Houve casos também em que o levantamento foi realizado via telefone, tendo o questionário como instrumento básico.

No início do questionário há informações a respeito da pesquisa, da UFPR e dos orientadores, além de um texto que apresenta de forma sucinta os objetivos da pesquisa. Aos entrevistados foi informado que os questionários não necessitavam ser identificados, ficando a critério exclusivo deles as informações pessoais. Na oportunidade, a eles foi garantido o anonimato, a fim de que pudessem responder às questões sem qualquer receio.

Também foi realizado um pré-teste dos questionários. Essa fase refere-se à aplicação prévia a um grupo que apresenta características da população incluída na pesquisa. Tem por objetivo revisar e 
direcionar aspectos da investigação, conforme ressalta Richardson (1999). Essa fase consumiu cerca de três semanas de trabalho. A versão original do questionário foi aplicada para cinco técnicos do sistema estadual de agricultura, três técnicos da iniciativa privada e três produtores rurais da região de Curitiba. A forma de aplicação foi a direta, por telefone e via e-mail. A análise dos questionários testados tornou possível a detecção e a correção de erros de inconsistência e complexidade, ambiguidade e perguntas desnecessárias. O pré-teste ocorreu no mês de dezembro de 2004 e janeiro de 2005. A aplicação dos questionários ocorreu a partir do mês de março de 2005, estendendo-se até o mês de setembro do mesmo ano.

\section{Tratamento, análise e interpretação dos dados}

Os dados secundários obtidos por fontes bibliográficas foram básicos para a constituição do referencial teórico da pesquisa. Serviram, ainda, para o estabelecimento da crítica necessária aos dados primários, à luz dos quais foram desenvolvidas as abordagens dentro da interdisciplinaridade dos saberes. Todo esse referencial visou à formulação de teorias que demonstram a presença ativa do ser humano como transformador da natureza e sua forma de inserção dentro desse processo de transformação.

Os dados primários, originados dos questionários através das perguntas fechadas, foram tratados estatisticamente e analisados de forma quantitativa, constituindo um arcabouço teórico que pudesse dar sustentação à argumentação crítica relativa às questões levantadas. Dessa forma, procurou-se traduzir a real percepção dos diversos atores pesquisados.

Com relação às questões abertas, procurou-se dar uma interpretação, discussão e classificação das mesmas levando-se em conta o referencial teórico estabelecido, assim como os objetivos pretendidos na pesquisa. Como princípio analítico, foi utilizada a análise de conteúdo, tendo como método o Discurso do Sujeito Coletivo (DSC), de Lefèvre (2000).

Quanto às escalas para os dados numéricos, nesta pesquisa o objetivo encontra-se mais direcionado à captar a percepção do público-alvo e relacioná-la em termos gráficos. Ressalte-se que, em grande parte das questões, ao invés de se solicitar o grau de relevância das diversas variáveis em relação à satisfação do entrevistado, optou-se por solicitar apenas se havia concordância quanto às alternativas ofertadas. Somente solicitava-se assinalar aquelas com as quais o entrevistado concordava. Interpretou-se a partir daí que as "não-escolhidas" também eram as "não-concordadas". Foi feita essa alternativa, tendo em vista que se desejava captar os "conceitos" dentro de um rol de alternativas preconcebidas, isto é, direcionando a uma percepção prévia dentro de contextos teóricos, e não o grau de satisfação do entrevistado quanto às questões apresentadas.

Assim, optou-se por procedimentos simples de análise estatística aplicada às ciências sociais, utilizando-se recursos gráficos e tabelas específicas. Além disso, foi desenvolvido um sistema de digitalização das informações com o objetivo de subsidiar o processo estatístico (frequências simples, frequências compostas, cruzamentos, médias e indicadores) e análises sobre a temática em questão. Em outras palavras, os dados obtidos pelas perguntas diretas, com alternativas, foram tabulados por intermédio de planilha Excel, sendo submetidos a uma análise simples, sendo apurados os percentuais de respostas em cada uma das variáveis tratadas. Foram utilizados dois tipos escala (nominal e ordinal). Para representação visual dos dados, o gráfico foi uma das formas escolhidas, tendo em vista constituir-se em um recurso visual da estatística que representa bem o fenômeno pesquisado. Tabelas também foram utilizadas.

A tabulação de todos os dados dos questionários em planilha eletrônica de Excel ocorreu de acordo com a classificação dos grupos de entrevistados e das questões.

Para a análise dos dados léxicos, foi adotada a metodologia do Discurso do Sujeito Coletivo (DSC). Trata-se de um método de processamento de depoimentos para ser usado em pesquisas de opinião, proposto por Lefèvre et al. (2000) na Universidade de São Paulo (USP). No DSC, as "peças" do quebracabeças são os extratos dos depoimentos que apresentam sentido semelhante, e a opinião coletiva é a "figura" formada pela "soma qualitativa" dessas "peças". Dessa forma, uma "soma qualitativa" pode ser entendida como a reunião, num único discurso, de extratos de respostas provenientes de diferentes indivíduos que apresentam sentidos semelhantes. Para realizar uma soma qualitativa e obter uma opinião coletiva, o DSC utiliza, para organização e tabulação dos dados, quatro figuras metodológicas, a saber: Expressões-Chave, Idéias Centrais, Ancoragens e Discurso do Sujeito Coletivo (LEFÈVRE, 2000, p. 17 19). Vale ressaltar que a ancoragem é o processo mais significativo dessa metodologia, por ser a prévia do 
DSC, pois "permite compreender a forma como os elementos contribuem para exprimir e constituir as relações sociais" (MOSCOVICI, 1961, p. 318), ou seja, a ancoragem contribui para dar sentido aos acontecimentos, pessoas, grupos e fatos sociais a partir da rede de significados oferecidos pelas representações sociais. Dessa forma, transforma o objeto estranho em algo familiar.

Entretanto, essa metodologia se presta muito bem quando o número de entrevistados não é muito extenso. Isso significa que ela deve sofrer uma pequena adaptação quando se deparar com um grande número de entrevistados. Assim, procedeu-se uma pequena alteração da metodologia proposta do DSC. De forma objetiva, foram estabelecidas quatro etapas:

a) RESPOSTA ORIGINAL - trata-se do ponto de partida para resgatar as percepções individuais para as perguntas abertas (questões léxicas do instrumento de coleta de dados), ou seja, a transcrição literal das entrevistas através de um processador de texto em computador (Excel).

b) INSTRUMENTO DE ANÁLISE DE DISCURSO 1 (IAD1) - EXPRESSÃO-CHAVE - este instrumento, como o próprio nome já define, descreve as expressões-chave que cada um dos indivíduos apresenta em seus discursos para cada resposta de uma dada pergunta.

c) INSTRUMENTO DE ANÁLISE DE DISCURSO 2 (IAD2) - IDÉIAS CENTRAIS - refere-se à listagem de todas as idéias centrais (em conformidade com as expressões-chave) para cada um dos sujeitos, relativamente às mesmas respostas de uma pergunta da entrevista, com total resgate da literalidade dos sujeitos em questão.

d) INSTRUMENTO DE ANÁLISE DE DISCURSO 3 (IAD3) DSC - ANCORAGEM - nessa última etapa, busca-se a organização das categorias de acordo com o agrupamento natural das falas (expressões-chave e idéias centrais) em torno do tema em discussão. Aqui se encontra a maior adaptação da metodologia, isto é, trata-se da formulação do Discurso do Sujeito Coletivo (DSC) através da transformação das várias expressões-chave no MENOR NÚMERO POSSÍVEL de FRASES DISCURSIVAS ( 3,4 ou 5 ) que possam representar o TODO COLETIVO (ao invés de UMA ÚNICA FRASE). É, portanto, a condensação de toda a fala de todos os entrevistados em um pequeno conjunto de frases expressivas, a partir das quais poderão ser tratadas de forma quantitativa.

\section{RESULTADOS E DISCUSSÃO}

A análise desses resultados teve como fonte alguns dados coletados de fontes bibliográficas documentais, assim como dos questionários aplicados na pesquisa de campo. Foram realizadas tendo como parâmetros a percepção média dos três grupos envolvidos (GOV, N-GOV e PROD).

Nesse contexto, pode-se deduzir que atualmente as PPR participam na CPM de diversas formas, porém sua maior participação é como fornecedora de matéria-prima (79\%). Embora essa forma de participação tenha sido substituída por outras, ainda vai prevalecer pelos próximos 20 anos (59\%). Porém, os entrevistados foram unânimes em afirmar que as PPR deverão ganhar mais de $10 \%$ da renda dentro da cadeia nos próximos 20 anos.

Dentre os principais motivos que dificultam a inserção das PPR na CPM os grupos destacam como o mais significativo a falta de informações técnicas, econômicas e de mercado (63\%), seguida da pouca assistência técnica governamental $(56 \%)$ e da falta de tradição e visão de longo prazo dos produtores $(53 \%)$. Significa que os produtores necessitam da maior proximidade do governo para melhorar sua capacitação e suas condições tecnológicas.

A questão da informação aos agricultores tem sido um dos maiores entraves para que eles possam se integrar de forma mais significativa nos processos de transformação da produção e, com isso, agregar mais valor ao seu produto. Esse problema é antigo e constitui um dos grandes desafios tanto da pesquisa quanto da extensão rural em todo o país. Não basta, por outro lado, apenas fazer chegar a informação ao agricultor: é preciso que ele saiba o que fazer com ela, além de dominá-la. Nesse sentido, Mattos $(2004$, p. 23) ressalta que "os principais entraves à competitividade da madeira e móveis são relacionados à matéria-prima, produção e vendas. Alguns pontos identificados dizem respeito (dentre outros) à necessidade de ampliar o apoio à pesquisa, documentação e informação tecnológica florestal".

Assim, sem informações técnicas e de mercado, o produtor florestal acaba por se tornar inviável na atividade, tendo em vista sua menor eficiência perante seus concorrentes. O próprio Programa Nacional de Florestas (PNF) ressalta esse problema como uma falha, isto é, escassez de dados econômicos sobre custos e benefícios do manejo de florestas nativas plantadas, bem como a falta de 
divulgação das informações existentes, gerando uma visão equivocada de que o manejo de florestas é economicamente menos atraente do que as atividades agropecuárias (BRASIL, PNF, 2000).

Esse problema, no entanto, está diretamente relacionado à qualidade da assistência técnica recebida pelos agricultores, fator fundamental para a tomada de decisão por parte deles, seja quanto às práticas de manejo, seja quanto à definição de cultivos, tendo por base as informações de mercado, de preços e de tecnologias, dentre outras. Ocorre que, historicamente, a assistência técnica às PPR no Brasil se dá por meio das empresas oficiais de extensão rural que, nas últimas décadas, dada à reestruturação administrativa dos estados e a instituição do neoliberalismo, vem se tornando cada vez mais reduzida ou até mesmo ausente, conforme observa Echenique (1998, citado por NEVES, 2005, p. 13): "Recentemente, a idéia de diminuição da presença do Estado na economia e a própria crise enfrentada pelos modelos utilizados influenciaram praticamente na extinção desse serviço. ' $80 \%$ do total dos estabelecimentos se encontram atualmente sem atendimento". Schmitz (2002, citado por NEVES, 2005, p. 13) complementa apontando "a falta de assistência técnica como um dos maiores problemas da agricultura, principalmente quando se constata a importância do setor na economia, especialmente a agricultura familiar, como também o seu impacto na alteração da paisagem e no manejo de recursos naturais".

$\mathrm{Na}$ área florestal, essa assistência ainda é mais limitada, dada a falta de técnicos especializados dentro das poucas estruturas de assistência técnica oficial ainda existentes no país, cujos reflexos recaem nas PPR. Finalmente, ainda no que se refere à falta de informação, vale assinalar que, de acordo com os aspectos legais, o produtor pode tornar-se até um "criminoso ambiental", dada a enorme quantidade de normas e regulamentos que tem de atender para continuar na atividade florestal.

Quanto aos fatores que interferem na integração da atividade silvicultural, a maior dificuldade assinalada foi a "falta de assistência técnica aos pequenos produtores rurais" (69\%). Pesa, ainda, sobre eles, a "baixa capacidade de investimento" (65\%), que dificulta a sua inserção no processo produtivo florestal. A falta de assistência técnica está relacionada às questões relativas à informação a respeito dos cultivos florestais produtivos, tanto tecnológica quanto de mercado e de sua rentabilidade, reforçando a necessidade de se melhorar as condições de produção das PPR para que possam participar mais da CPM.

No que se refere às dificuldades das PPR em expandir a base florestal produtiva, ressalta-se que no próprio PNF também se observam alguns entraves para essa expansão, como, por exemplo, a inadequação das políticas públicas, que, em sua maioria, encontram-se voltadas mais à expansão agropecuária, exigente de grandes desmatamentos (BRASIL, PNF, 2000). Por outro lado, a Abimci (2005) chama a atenção para o fato de que, no passado, existia uma percepção negativa que vinculava a indústria de madeira à degradação ambiental. Entretanto, essa percepção vem mudando gradativamente. Assim, observa-se, pela figura 1, que a maior dificuldade para essa expansão também reside na "falta de informações técnicas" (26\%).

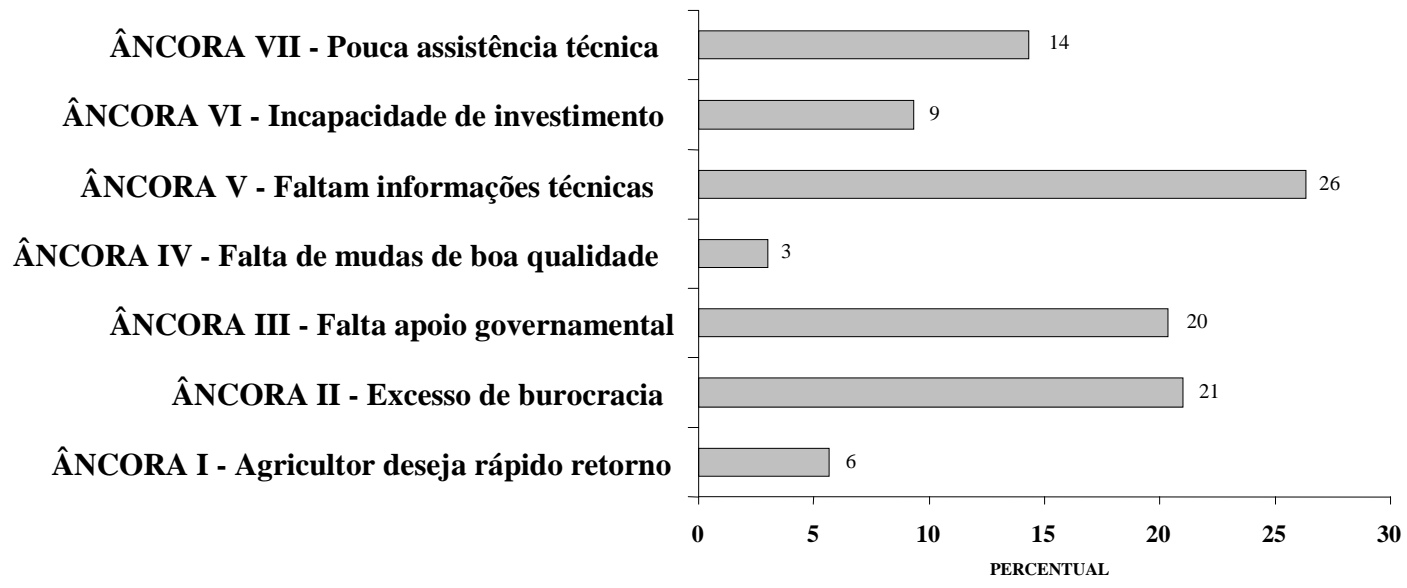

Figura 1. Preferência das sete âncoras do DSC sobre as dificuldades que reprimem a expansão da base florestal produtiva, na percepção dos grupos pesquisados.

Figure 1. Preference of seven anchors of the DSC on the difficulties that repress the expansion of the forest productive base, in the perception of the investigated groups. 
Outro fator de dificuldade associado à falta de informação, é a falta de apoio governamental. Essas duas questões encontram-se associadas à restrita estrutura do corpo profissional da Seab, a partir do momento em que o ITCF (Instituto de Terras, Cartografia e Floresta), que, em parte, respondia às demandas do setor, destinou-se para o IAP (Instituto Ambiental do Paraná), instituição da Secretaria do Meio Ambiente (via Lei $n^{\circ}$ 10.066/92). Desde aquele ano, a Seab não investiu mais em recursos humanos específicos na área florestal, como pode ser observado na figura 2, que representa a estrutura de recursos humanos na Seab, Sema, Emater e IAP em 2005.

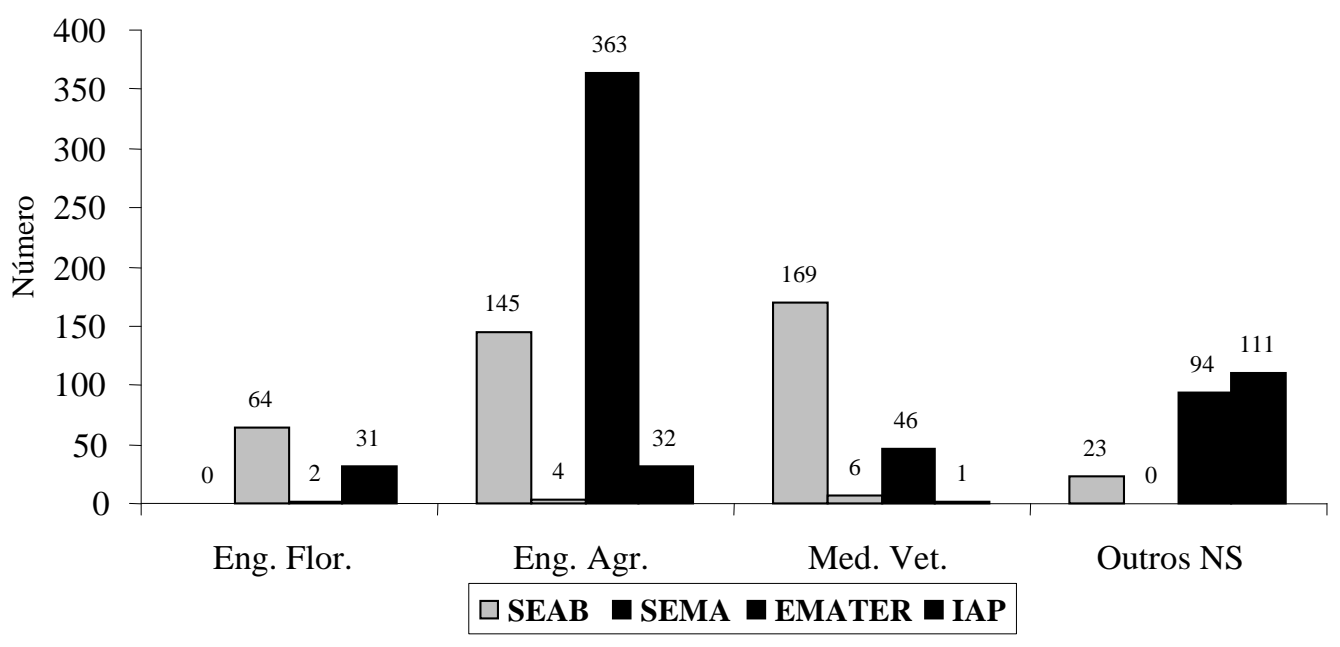

Fonte: GRHS da SEAB, SEMA, EMATER e IAP (Março, 2006)

Figura 2. Comparativo da estrutura atual do corpo funcional da Seab, Sema, Emater e IAP (2005).

Figure 2. Comparative of the current structure of the functional body of the Seab; Sema; Emater and IAP (2005).

Pode-se observar que a concentração de engenheiros florestais encontra-se apenas na Sema e no IAP. Por outro lado, tanto a Emater, com apenas dois florestais, quanto a SEAB, sem nenhum, não dispõem de estrutura suficiente para a condução de uma política florestal que possibilite a expansão da base florestal no estado e, tampouco, de promover a inserção das PPR na CPM. Vale ressaltar, no entanto, que apenas a variável "estrutura funcional" é insuficiente para se definir uma política florestal (faltariam, ainda, uma lei, uma estrutura funcional, um programa e um fundo, entre outros fatores), mesmo porque há profissionais capacitados de outras categorias que poderiam estabelecer e conduzir tal política. O que se poderia observar é que a ausência desse tipo de profissional (engenheiro florestal) no setor produtivo, mas presente no setor ambiental do Estado, pode ser um indicador de que tal política estará associada mais aos aspectos de conservação e reposição do que da produção madeireira. Por outro lado, também não se pode afirmar que, pelo fato de não existência desse tipo de profissional nos quadros da Seab e Emater, o setor produtivo não esteja sendo fomentado. Tanto assim, que há várias ações da Seab/Emater em conjunto com empresas do setor de base florestal e de representantes dos agricultores rurais, nas quais se fazem presentes tanto a extensão florestal como o estímulo ao plantio de florestas produtivas. Nesse caso, podese citar os seguintes projetos e suas respectivas regiões (PINTO, 2005): a) Inpacel e outras - região de Arapoti; b) MASISA, Águia, Rickli e outras - região de Ponta Grossa; c) Klabin, polo moveleiro - região de Telêmaco Borba; d) Iguaçu e outras - região de Piraí do Sul; e) Pisa, Placas e outras - região de Jaguariaíva; f) Tafisa e outras - polo moveleiro de São Bento do Sul (SC); g) Polo madeireiro de Guarapuava, Ibema; Sta. Maria, Repinho e outras; h) Polo madeireiro de União da Vitória; i) Polo moveleiro de Cascavel e Toledo; j) Polo moveleiro de Umuarama - $2^{\circ}$ polo moveleiro do Paraná; k) Polo moveleiro de Arapongas $-1^{\circ}$ polo moveleiro do Brasil; 1) Araupel e outras - região de Quedas do Iguaçu - oeste. 


\section{CONSIDERAÇÕES FINAIS}

Tendo por base as percepções dos atores pesquisados (Gov; N-Gov e Prod), conclui-se que:

- Os pequenos produtores rurais recebem pouco apoio governamental, notadamente quanto aos serviços de assistência técnica e de informações de produção, de mercado e legislação, dificultando sobremaneira a sua inserção na CPM. Essa deficiência do governo fica ainda mais relevante ao se considerar que o plantio florestal é uma atividade cujo retorno econômico é de médio e longo prazo, o que significa que há necessidade de maior capacitação dos agricultores em termos de educação, conscientização e de visão de futuro. Essa questão se reveste de grande importância na medida em que se constata que os maiores entraves para a viabilização dos empreendimentos das PPR, além das limitações de recurso, advêm, sobretudo, da sua pouca articulação com o mercado. Significa que o seu conhecimento a respeito dos canais e mecanismos de comercialização fica restrito, praticamente, ao mercado local, tornando-se, na maioria das vezes, dependentes dos intermediários, que pagam pouco pelos seus produtos. Essa constatação serve para confirmar a primeira hipótese da pesquisa, cuja premissa era a de que falta apoio do governo quanto à informação e à assistência técnica. Decorrente disto, pôde-se verificar ainda:

- que os agricultores têm consciência de que a sua participação financeira é baixa dentro da cadeia produtiva da madeira, porém esperam que, nos próximos 20 anos, essa participação possa aumentar significativamente;

- que a atividade silvicultural, que deveria assegurar a geração de emprego e renda às PPR, não é mais encarada como uma atividade que possa garantir a sua aposentadoria;

- a urgência da expansão da base florestal, por meio da inclusão das pequenas propriedades rurais ao processo de formação e manejo de florestas de forma sustentável;

- que, por se tratar de uma atividade cujo retorno econômico é de médio e longo prazo, as alternativas de financiamento e de mecanismos simplificados de acesso ao crédito para os pequenos produtores rurais são imprescindíveis para integrá-los ao processo de produção florestal.

\section{REFERÊNCIAS}

ASSOCIAÇÃO BRASILEIRA DA INDÚSTRIA DE MADEIRA PROCESSADA MECANICAMENTE (ABIMCI). A questão florestal e o desenvolvimento. Disponível em: <http://www.bndes.gov.br/conhecimento/seminario/florestal9.pdf>. Acesso em: 13/07/2005.

AICHER, C. A política florestal européia: um sonho ou uma realidade? Ciência Florestal, Santa Maria, v. $14, \quad$ n. $2, \quad$ p. 177-188 177, 2004. Disponível em: <http://www.ufsm.br/cienciaflorestal/artigos/v14n2/A17V14N2.pdf>. Acessado em: 25/08/2005.

ANGELO, H. Implicações da certificação florestal na competitividade da madeira tropical brasileira no mercado internacional. Brasília, DF: MMA, 2002.

ANTUNES, L. F. C. O procedimento administrativo de avaliação de impacto ambiental. Coimbra: Livraria Almedina, 1998.

ASSOCIAÇÃO PARANAENSE DE EMPRESAS DE BASE FLORESTA (APRE). Silvicultura apresenta evolução. Revista da Madeira, Curitiba, n. 80, abr. 2004.

BARDIN, L. Análise de Conteúdo. Lisboa: Edições 70, 1979.

BANCO REGIONAL DE DESENVOLVIMENTO DO EXTREMO SUL (BRDE). Florestamento na região sul do Brasil: uma análise econômica. Disponível em: 〈http://brde.com.br/estudoepub.pdf〉. Acesso em: 26/07/2006.

BARBETTA, P. A. Estatística aplicada às ciências sociais. 5. ed. Florianópolis: UFSC, 2002. 
BRASIL. Ministério do Desenvolvimento Agrário (MDA). Aprovado o Projeto de Lei da agricultura familiar. Disponível em: <http://www.mda.gov.br/index.php?sccid=134\&ctuid=9735> Acesso em: 20/09/2006.

CAMARGO, C. de B. Técnicas de análise do comportamento de consumidores. Florianópolis: LABPLAN/CTC/UFSC, 2000. Apostila em elaboração.

CHISNALL, P. M. Pesquisa mercadológica. Rio de Janeiro: Saraiva, 1980.

CHURCHILL JUNIOR., G. A. Marketing research: methodological foundations. Chicago: The Dryden Press, 1987.

DEMO, P. Combate à pobreza: desenvolvimento como oportunidade. Campinas, SP: Autores Associados, 1996.

. Metodologia do conhecimento científico. São Paulo: Atlas, 2000

EMBRAPA. Centro Nacional de Pesquisa de Florestas Cooperação interinstitucional para o desenvolvimento rural sustentável no Estado do Paraná: o caso da Agenda-Comum entre Embrapa Floresta \& Emater-Parana / Vanderley Porfírio da Silva, Amauri Ferreira Pinto. Colombo, 2005.

FAUZE, N. M. Pesquisa de marketing. Edição compacta. São Paulo: Atlas, 1996.

FOOD AND AGRICULTURE ORGANIZATION OF THE UNITED NATIONS (FAO). Incentivos e Mecanismos Financeiros para o Manejo Florestal Sustentável na Região Sul do Brasil. Relatório: MENDES, Jefferson B. R03_FAO_01_MECANISMOS_FINANCEIROS. Curitiba, 06 de Fevereiro de 2004.

FOREST STEWARDSHIP COUNCIL (FSC). Conselho de Manejo Florestal. Relatório de Atividades 2004-Brasil. Disponível em: <http://www.fsc.org.br/arquivos/relatorio\%20de\%20atividades\%20FSC\%202004.doc〉. Acesso em: 25/07/2005.

_. Os 10 princípios e critérios do FSC-Brasil. Disponível em: $\langle$ http://www.fsc.org.br/arquivos/P\&C\%20originais\%20portugu\%C3\%AAs.doc $>$ Acesso em: 22/08/2006.

FUNDAÇÃO DE DESENVOLVIMENTO DA PESQUISA (FUNDEP). Aumento da desigualdade no mundo. Disponível em: <http://www.fundep.ufmg.br/homepage/noticias/4090.asp>. Acesso em: 15/01/2006.

FUNDO DAS NAÇÕES UNIDAS PARA A INFÂNCIA (UNICEF). Mais de 27 milhões de crianças vivem na pobreza no Brasil. Folha de São Paulo, 2004. Disponível em: <http://premioethosvalor@yahoogroups.com> Acesso em: 10/02/2006.

GIL, A. C. Métodos e técnicas de pesquisa social. São Paulo: Atlas, 1999.

INSTITUTO BRASILEIRO DO MEIO AMBIENE E DOS RECURSOS NATURAIS RENOVÁVEIS (IBAMA). Programa Nacional de Florestas-PNF. Brasília, DF, 2000. 52 p.

_. Diretrizes para utilização de recursos florestais. Disponível em:

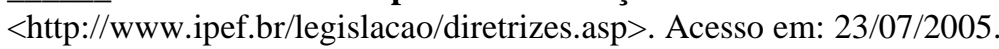

Ministério do Desenvolvimento Agrário. Aprovado o Projeto de Lei da agricultura familiar. Disponível em: <http://www.mda.gov.br/index.php?sccid=134\&ctuid=9735>. Acesso em: 20/09/2006.

INSTITUTO PARANAENSE DE DESENVOLVIMENTO ECONÔMICO E SOCIAL (IPARDES). Paraná: diagnóstico social e econômico. Curitiba, 2003.

KENGEN, S. Certificação de produtos florestais. Disponível em: $<\mathrm{http}: / /$ www.redeambiente.org.br/Opiniao.asp?artigo=50>. Acesso em: 25/08/2005. 
LEFEVRE, F.; LEFEVRE, A. M. C. O Discurso do Sujeito Coletivo (DSC). Um novo enfoque em pesquisa qualitativa. (Desdobramentos). Caxias do Sul: Educs; 2003.

LEFÈVRE, F.; LEFÈVRE, A. M. C.; TEIXEIRA, J. J. V. (Orgs.). O discurso do sujeito coletivo: uma nova abordagem metodológica na pesquisa qualitativa. Caxias do Sul: EDUCS; 2000.

MATTOS, P. P.; SCHAITZA, E. G.; AHRENS, S. Certificação Florestal em pequenas propriedades. Disponível em: 〈http://www.cnpf.embrapa.br/publica/arqgrat/com_tec92.pdf>. Acesso em: 25/08/ 2005.

MATTOS, P. P. de; SILVA, V. P. da; MAGALHÃES, W. L. E. Agregação de valor à pequena produção florestal madeireira. Colombo: EMBRAPA Floresta, 2004.

MENDES, R. H. Caracterização do perfil dos proprietários rurais, da região do planalto serrano catarinense. 181 f. Dissertação (Mestre em Engenharia Florestal) - Setor de Ciências Agrárias, Universidade Federal do Paraná, Curitiba, 2005.

MOSCOVICI, S. La Psychanalyse son image et son public. Paris: Presses Universitaires de France, 1961.

NEVES, D. P. Campesinato e reenquadramentos sociais: os agricultores familiares em cena. Revista Nera, Presidente Prudente, v. 8, n. 7, jul./dez. 2005.

PARANÁ. Secretaria de Estado da Agricultura e do Abastecimento (SEAB). Departamento de Economia Rural (DERAL/DEB). Valor bruto da produção agropecuária paranaense. Curitiba, 2003.

Valor bruto da produção agropecuária paranaense. Curitiba, 2005.

PINSONNEAULT, A.; KRAEMER, K. L. Survey research methodology in management information systems: in assessment. Journal of Management Information Systems, Autumn, v. 10, n. 2, p. 75-105, 1993.

QUEIROZ, A. F. Proteção constitucional da pequena propriedade rural. Revista eletrônica Jus navigandi, 2000. Disponível em: <http://jus2.uol.com.br/doutrina/texto.asp?id=1676>. Acesso em: $15 / 08 / 2006$.

RICHARDSON, R. J. Pesquisa social: métodos e técnicas. São Paulo: Atlas, 1999.

SARACENO, E. Alternative readings of spatial differentiation: The rural versus the local economy approach in Italy. European Review of Agricultural Economics., Amsterdam, n. 21, p. 451-474, 1994.

SOCIEDADE BRASILEIRA DE SILVICULTURA (SBS). O setor florestal brasileiro crescimento das cadeias produtivas: expansão da base florestal. Nelson Barboza Leite IN: SEMINÁRIO “A QUESTÃO FLORESTAL E O DESENVOLVIMENTO”. Rio de Janeiro: BNDES. 08 de julho de 2003.

SILVA, J. G. da. O novo rural brasileiro. 2. ed. Campinas: Unicamp-IE, 1999. (Coleção Pesquisas)

SPOSATI, A. (Coord.). Mapa da exclusão-inclusão social da cidade de São Paulo: dinâmica social dos anos 90. São Paulo: PUC de São Paulo: INPE, 2000.

TRIVIÑOS, A. N. S. Introdução à pesquisa em ciências sociais: a pesquisa qualitativa em educação. São Paulo: Atlas, 1987.

VEIGA, J. E. da. Cidades imaginárias: o Brasil é menos urbano do que se calcula. Campinas, SP: Autores Associados, 2002.

YAMAMOTO, O. H. Questão social e políticas públicas: revendo o compromisso da Psicologia. In: ANA M. B. B. (Org.). Psicologia e compromisso social. São Paulo: Cortez, 2003. p. 37-54. 